\title{
Metodologias de análisis del espacio audiovisual online: Entre la innovación y la ansiedad de la novedad
}

\author{
Methodologies for the analysis of online audiovisual \\ space:Between innovation and anxiety of novelty
}

\author{
IgOR SÁDABA \\ Universidad Complutense Madrid \\ igor.sadaba@cps.ucm.es (ESPAÑA) \\ CÉsAr Rendueles \\ Universidad Complutense de Madrid
}

(ESPAÑA)

Recibido: 29.06 .2016
Aceptado: 19.09 .2016

\section{RESUMEN}

La aparición de espacios digitales que incluyen grandes bases de datos de videos online ha generado una serie de innovaciones metodológicas y prácticas emergentes que suelen venir acompañadas de discursos esperanzadores y profecías sobre el papel de los medios online en la investigación social. Este medioambiente discursivo ha alterado sensiblemente la recepción y evaluación de lo que podríamos denominar las metodologías audiovisuales. En este artículo, a partir de una serie sencilla de rasgos específicos de las plataformas de videos en Internet (principalmente Youtube) se ha intentado catalogar una serie de modelos de investigación audiovisual o de prácticas de producción e interpretación de materiales audiovisuales en el entorno de las ciencias sociales. El objetivo es identificar sus rasgos distintivos y sus potencialidades epistemológicas sacando a la luz, además, algunos de sus presupuestos tácitos. Se trata, en última instancia, de una evaluación constructiva de estos modelos de investigación que a través del análisis de sus hipótesis subyacentes aspira a contribuir al correcto aprovechamiento de las oportunidades metodológicas que ofrecen los repositorios audiovisuales online. 


\title{
PALABRAS CLAVE
}

Metodología audiovisual, Audiovisual online, Youtube, Innovaciones metodológicas, comunidades virtuales.

\begin{abstract}
In recent times the emergence of digital spaces and large databases of online videos has generated a great number of methodological innovations. Such research practices also are frequently accompanied by encouraging speeches and prophecies about the role of online media in social research. Thus, what we call audiovisual methodologies have been transformed and altered. In this article, from a simple set of specific features of the platforms of videos on the Internet (Youtube mainly) we have tried to identify a number of models of audiovisual research or production practices and interpretation of audiovisual materials in the field of Social Sciences. Through its description and demonstration of their essential distinctive features and theoretical and methodological assumptions we will try to challenge them for a constructive criticism of this type of research proposals. The core idea we take is that questioning these bases and underlying assumptions is necessary to advance a sociological practice who really take advantage of the methodological opportunities around the online audiovisual repositories.
\end{abstract}

\section{KEY WORDS}

Visual methodologies, online video, Youtube, methodological innovations, virtual communities

\section{INTRODUCCIÓN}

En apenas unos años la investigación online ha experimentado un inmenso crecimiento. La era del Big Data (Cukier y Mayer-Schönberger, 2013) y el acceso a registros masivos de información -datos naturales no intrusivos, como los rastros que se dejan en los espacios virtuales- han suscitado grandes expectativas respecto a su rendimiento inminente en el campo de la investigación social (Hine, 2005; Beddows, 2008; Fielding et al. 2008; Marhkam y Baym, 2008; Poynter, 2010; Estalella y Ardévol, 2011), así como encendidos debates éticos (Eynon et al., 2009 y Whiteman, 2012). Lo cierto es que los procesos de digitalización que están transformando los ámbitos laborales, políticos o relacionales, afectan también a la propia forma de producir, gestionar e interpretar la información que nos rodea. Por ello, no sólo se han revitalizado algunos terrenos teóricos y aplicados, como el análisis de redes, sino que han aparecido nuevas técnicas de investigación -la etnografía virtual (Hine, 2004 
y 2015), sin ir más lejos- y fuentes de datos originales y desconocidas (blogs, redes sociales digitales, webs, datos de audiencias, etc.).

Sería absurdo, por tanto, negar que estamos asistiendo a una ampliación real de las estrategias de investigación social en el campo digital. No obstante, también es cierto que la digitalización metodológica a menudo ha estado rodeada de una retórica futurista ambigua, que no siempre permite diferenciar con precisión la realidad, las esperanzas y las falsas promesas (Estalella y Ardevol, 2011). Algo similar a lo que ha ocurrido con las metodologías visuales predigitales (fotografía, cine etnográfico, etc.) en su incorporación al corpus de las ciencias sociales (Rose, 2016). Las nuevas oportunidades metodológicas o epistemológicas que en principio ofrece esta transformación no conducen necesariamente a avances empíricos significativos. Como a menudo ocurre en nuestras disciplinas, no es raro que se abra un abismo entre la cruda realidad práctica y la utopía metodológica, en especial, cuando entran en juego técnicas de análisis altamente sofisticadas y conjuntos de decisiones relevantes que afectan a todo el proceso investigador. Como sugiere Christine Hine, hay que estar alerta contra la "ansiedad metodológica" (Hine, 2005: 3-6), pues la traducción de las técnicas y métodos de investigación clásicos a espacios u objetos novedosos no tiene por qué dar los resultados esperados. En general, las oportunidades de financiación y de práctica investigadora rápida y aparentemente aséptica han hecho que la investigación de mercados y el marketing hayan abrazado sin temor la investigación online (Kozinets, 2015). Sin embargo, el campo académico, siempre más prudente y receloso de las novedades, se encuentra atravesado por posturas encontradas y disputas algo enmarañadas.

Este artículo propone una evaluación metodológica de los usos del audiovisual online en la investigación social. Entendemos por "audiovisual online" la existencia de material fílmico masivo almacenado en espacios digitales-virtuales (Internet mayormente). En concreto, se intentará identificar una serie de áreas de investigación vinculadas al vídeo digital, organizadas en función de sus categorías teóricas y metodológicas medulares. De este modo, saldrán a la luz y se analizarán críticamente algunos presupuestos subyacentes a esta clase de propuestas que suelen pasar desapercibidos. El objetivo final es avanzar tentativamente hacia un juicio equilibrado en torno a los pros y contras metodológicos del empleo en ciencias sociales de los catálogos de vídeos online a la carta, evitando las posiciones maximalistas de uno u otro signo y tratando de contribuir a un debate sereno. 


\section{LOS REPOSITORIOS DIGITALES Y LA CULTURA YOUTUBE COMO FENÓMENO SOCIAL}

En apenas una década la plataforma Youtube, creada en 2005, se ha convertido -junto con sus hermanos menores Vimeo, Vube, Dailymotion o Yahoo Screen ${ }^{1}$ - en un fenómeno audiovisual sin precedentes ya meramente en términos cuantitativos. Según se informa en su propia web, "YouTube tiene más de mil millones de usuarios (para hacerse una idea, equivaldría a un tercio de todos los usuarios de Internet) y cada día se ven cientos de millones de horas de vídeos y se generan miles de millones de reproducciones"2. Seguramente no es exagerado afirmar que estos repositorios colaborativos han transformado profundamente el papel que desempeñan los medios audiovisuales en la vida de millones de personas y en la manera de producir, distribuir y consumir esos materiales. Hay que tener en cuenta que estamos hablando del tercer sitio web más visitado del mundo (tras Google y Facebook), "cada minuto se suben a YouTube 100 horas de vídeos" y "cada mes se ven en YouTube más de 6.000 millones de horas de vídeo, lo que equivale a casi una hora de vídeo por cada habitante de la Tierra"'. Incluso en España, Youtube es la web con más visitantes únicos por encima de todos los periódicos o de Twitter dentro de las páginas que controla el EGM (lo que excluye buscadores) 4 $^{4}$.

Más allá de estas cifras abrumadoras, Youtube tiene algunas características distintivas que han interesado a numerosos investigadores sociales, en especial, aquellos aspectos relacionados con los procesos de construcción colectiva de los procesos audiovisuales y con la dimensión participativa tanto de la generación y publicitación de contenidos como del visionado y consumo audiovisual (Burgess y Green, 2009). Son muchos los autores que inciden en la propiedad cooperativa como un rasgo formal que determina la naturaleza de Youtube por encima de sus contenidos sustantivos (Jenkins, 2006; Gaudenzi, 2014; Yang, 2013, Bloom y Johnston, 2013). Lo visual, como tal, pierde su centralidad en favor del continente o recipiente. Desde esta perspectiva, se suele hacer énfasis en la idea de que se trata de un medio abierto en el que usuarios de cualquier parte del mundo pueden compartir casi sin restricciones sus producciones. Dicho de otra manera, la propia arquitectura de estas plataformas cuestiona el enfrentamiento tradicional entre las categorías de creador y audiencia. Se trataría de una emancipación audiovisual que surge como un subproducto involuntario de la tecnología y universaliza la posibilidad de producción/ subida y descarga/reproducción. Las plataformas tipo Youtube serían la representación paradigmática de la "cultura participada" (Chau, 2010). De este modo, se rompe el monopolio massmediático tradicional y se crea un oasis de libertad y experimentación audiovisual colectiva en el que se estaría forjando

1 Para un panorama general sobre las diferentes plataformas de vídeo online véase Purcell (2010).

2 https://www.youtube.com/yt/press/es/statistics.html

3 http://www.cmo.com/features/articles/2014/5/19/mind_blowing_stats_youtube.html

4 http://www.aimc.es/-Datos-EGM-Resumen-General-html (EGM, marzo 2016).

EMPIRIA. Revista de Metodología de Ciencias Sociales. N. ${ }^{0}$ 35, septiembre - diciembre, 2016, pp. 105-124. ISSN: 1139-5737, DOI/ empiria.35.2016.17170 
una inmensa videoteca digital borgiana. Por ello, para muchos autores, el rasgo central y definitorio de Youtube y otros medios afines es su estructura descentralizada que ha permitido la autonomía de la audiencia que habría adquirido, por primera vez en la historia del audiovisual, una gran soberanía en términos de concepción, elaboración, distribución y consumo ${ }^{5}$ (Jenkins, 2006 y Castells, 2009). De este modo, las audiencias serían no sólo un reflejo de lo social (Callejo, 2001: 20) sino una especie de sujeto histórico privilegiado de la globalización hipertecnológica que, no en vano, Castells denomina "era de la autocomunicación de masas" (Castells, 2012).

Lo cierto es que hasta ahora la producción y difusión audiovisual estaba marcada por una gran cantidad de cuellos de botella, barreras de acceso tecnológicas y económicas que abonaban el terreno para algunas de las prácticas oligopólicas más importantes de las sociedades contemporáneas, como los megaoligopolios hollywoodienses y las corporaciones mediáticas. Por eso la era digital del "audiovisual para todos" y el vídeo DIY (Do It Yourself) a veces se ha interpretado como un proceso de homogeneización de la labor fílmica que ha abierto el rol del cineasta al ciudadano conectado, permitiendo a cualquier lego ejercer de director por un día. Los requisitos técnicos y las destrezas necesarias para abrir un canal de Youtube y grabar con algún dispositivo (smartphone, tablet, cámara...) son comparativamente mínimos y accesibles a casi cualquiera. Esta "democratización" del vídeo online terminaría con el monopolio de la práctica audiovisual legítima -hasta ahora en manos de industrias visuales, productoras, cadenas y artistas o especialistas- popularizando el rodaje casero, que se caracteriza no tanto por la rebaja de las exigencias técnicas o de calidad como por la dislocación de los papeles clásicos que relegaban las masas a ser receptoras pasivas.

Teniendo en cuenta esto, desde un punto meramente descriptivo, podemos identificar en estas bibliotecas audiovisuales tres características distintivas: i) su acceso público (gratuito, global e inmediato) tanto para subir materiales audiovisuales como para descargarlos, ii) su volumen, con cantidades inabarcables de materiales y videos, iii) su carácter amateur y no profesional en su mayor parte ${ }^{6}$. Tomando estas categorías como punto de partida, a continuación se propone un modesto intento taxonómico de las posibilidades metodológicas y epistemológicas que abren los nuevos repositorios audiovisuales, es decir, de algunas de principales estrategias de estudio y análisis que se han desarrollado en este campo y sus presupuestos ocultos. Estos tres grandes rasgos no solo definen los "modos de ver" (Berger, 2008) sino, por extensión, los modos de investigar.

5 Para Jenkins, el fenómeno que tiene lugar se denomina "convergencia mediática" y viene a ser un conjunto de procesos en los que se "altera la relación entre las tecnologías existentes, las industrias, los mercados, los géneros y el público... afectando tanto el modo de producción como el modo de consumo de los medios" (2006: 14 y 26-27).

6 Una búsqueda en octubre de 2013 con la etiqueta "funny" dio más de 80 millones de vídeos. Ocurre lo mismo con "fails" o "caídas", lo que ha llevado a algunos autores a denominar este género como "vídeos banales" (Moreno, 2014:25). 


\section{DEMOCRATIZACIÓN AUDIOVISUAL Y AUDIENCIAS VISIBLES E INMEDIATAS}

Subir, descargar y compartir vídeos se ha convertido en una nueva práctica social basada no solo en las comunidades de intereses y grupos de afinidad tradicionales -como podían ser los grupos amateur de fotografía y vídeo analógicos- sino en la conexión digital de multitudes dispersas. Buena parte de los análisis sociales del audiovisual digital se mueven en el entorno de las teorías acerca de la sociedad red (Castells, 1999), es decir, como parte de vínculos sociales de nueva generación basados en una conectividad frágil pero extremadamente abundante y sistemáticamente mediados por las tecnologías de la comunicación. La circulación planetaria del audiovisual y su consumo compartido masivo saca a la luz el modo en que las comunidades digitales globalizadas interaccionan de diversas formas (boyd y Ellison, 2012). Esta familia de análisis, por tanto, se centra no tanto en el contenido concreto del vídeo como en los procesos de interacción entre miles o millones de usuarios a través de plataformas en las que el intercambio de experiencias audiovisuales genera relaciones sociales de distinto tipo.

Las potencialidades participativas de la estructura tecnológica de Youtube y plataformas similares han disparado entonces las técnicas de producción y análisis de datos basados en estas "comunidades monitorizadas". Por ejemplo, la introducción de la funcionalidad de "respuestas" (responses) en marzo de 2006 preparó el terreno para nuevos tipos de interacción mediada que podían observarse y leerse directamente. Así, Adami (2010) registró durante catorce meses los gráficos de vídeos "más respondidos" y leyó las hebras de comentarios con el objeto de elaborar una tipología conversacional. El estudio de estas respuestas como coloquios informales que a veces se convierten en hablas caóticas pero cuyas geometrías complejas llevan a la construcción colectiva de sentidos coherentes se ha convertido en una vía de estudio sugerente. Lo mismo ocurre con la aplicación de todo tipo de técnicas de análisis de contenido a estos foros de opinión sobre los vídeos a fin de detectar cuestiones como el engagement (Kavada, 2010) o el MSV (message sensation value) (Paek et al. 2010). En estas investigaciones se emplean fórmulas sofisticadas para tratar de detectar la emocionalidad de los comentarios y las reacciones sentimentales de una audiencia difusa como por ejemplo en las 12.161 respuestas a los 50 videos pro-anorexia más populares (Oksanen et al. 2015).

Precisamente, uno de los principales desafíos a los que se enfrentan estos análisis es que tienen que lidiar con audiencias cuya identidad empírica, a diferencia de lo que ocurría con los medios tradicionales, carece de contornos bien definidos. Un problema de credibilidad y autenticidad que ya señalaron en su momento otras incipientes investigadoras del universo Internet al comenzar a realizar entrevistas online a través del email o de foros web (James y Busher, 2013). Se trata de colectividades vagas y con vínculos borrosos pero a las que, no obstante, se les presupone la capacidad de crear normas, significados y una cierta protoinstitucionalidad. De hecho, se ha llegado a definir 
estas plataformas en las que los usuarios anónimos difunden e intercambian contenidos audiovisuales negociando criterios, clasificaciones y opiniones sobre los vídeos como medios "community-driven" (Geisler y Burns, 2007), ya que el crecimiento exponencial de materiales compartidos se debe, al menos en parte, a las características de este tipo de agregación reticular. Por eso el monitoreo del comportamiento de la comunidad mediante distintos indicadores ha sido una veta de investigación que se ha explotado con ahínco para tratar de descubrir pautas de autorregulación y tendencias subyacentes del tráfico de información, incluyendo análisis de contenido sobre los vídeos producidos por diferentes grupos sociales, como el tercer sector (Arroyo et al. 2013), o clasificados bajo ciertas etiquetas: "divertidos" (Moreno, 2014), de "info-entretenimiento político" (Berrocal, Campos y Redondo, 2012), etc. En general, la disputa metodológica se centra en establecer cuáles son las métricas precisas o las medidas más inspiradoras para radiografiar estas videocomunidades.

De hecho, tal vez la principal limitación de este tipo de análisis es que a veces tienden a tratar la noción de "comunidad online" como un hecho aproblemático, cuando seguramente es más bien una metáfora resbaladiza. Seguramente la comprensión de los procesos agregados digitales mediante analogías con los actores sociales tradicionales es inevitable pero también tiene límites evidentes. No sólo los vínculos sociales que se establecen en las redes digitales son muy idiosincrásicos sino que mantienen relaciones profundas con otros procesos sociales contemporáneos. Las multitudes online, por muy inteligentes que sean (Rheingold, 2004), responden a complejos procesos de configuración e interacción. Las "comunidades" digitales creadas en torno a la producción audiovisual no viven aisladas de los procesos de mercantilización -Youtube, al fin y al cabo, es una empresa-, individualización y consumo contemporáneos. En última instancia, la hipótesis fuerte de que se pueden describir tales comunidades a partir de un conjunto de comentarios o de ciertos indicadores no deja de atribuir a esas expresiones y constructos una grupalidad nada evidente (no necesariamente constante en el tiempo, estable o duradera). En general, adscribimos valores y manifestaciones culturales a objetos sociológicos no identificados con la esperanza de que su semejanza a la solidez offline no deba probarse. Un ejemplo es la idea de "discurso digital" (Thurlow y Mroczek, 2011 y Androutsopoulos, 2011) que atribuye similitudes lingüísticas a prácticas comunicativas muy diferentes, asimilando un conjunto disperso de escrituras anónimas breves con enunciaciones orales de un único sujeto ${ }^{7}$.

7 Por ejemplo, el comentario típico de Youtube tiende a ser medianamente positivo, publicado por un varón de unos 29 años y contiene 58 caracteres de media. Y solo un $23 \%$ suelen ser respuestas a otros comentarios (solo 1 de cada 4 genera debate con otros usuarios, por tanto) (Thewall et al., 2012). 


\section{ETNOGRAFÍA AUDIOVISUAL Y BANALIDAD DIGITAL}

Desde la perspectiva de una amplia corriente de investigaciones, las bibliotecas digitales contemporáneas son una vía de acceso a la realidad social mucho más inmediata que los medios audiovisuales tradicionales. Los vídeos autoproducidos de Youtube proporcionan una abrumadora cantidad de materiales carentes de los filtros técnicos característicos de las producciones cinematográficas y televisivas. Serían, por tanto, una manifestación virtuosa de la "espontaneidad de la acción", una fuente de naturalidad y sinceridad sociológica (Moreno, 2014: 26). Hasta el punto de que la franqueza del amateur que muestra su cotidianeidad en sus vídeos caseros ha sido entendida como una vuelta al corazón del "documental etnográfico". El contenido banal de gran cantidad de estos vídeos -imágenes de mascotas, caídas o escenas humorísticas...- no sería, por tanto una limitación para su aprovechamiento sociológico sino, al contrario, un sello de autenticidad naturalista y objetividad que sacaría a la luz el exotismo de lo cotidiano. Es lo que algunos analistas de medios han denominado "el culto al amateur" (Keen, 2011) en referencia también a blogs y redes sociales donde personas anónimas toman la palabra para relatar su día a día. Jean Burgess ha bautizado estos espacios con la expresión "vernacular creativity", que emplea para describir prácticas creativas no elitistas que emergen de contextos nativos, cotidianos y específicos (Light et al., 2012). De hecho, el slogan de lanzamiento de Youtube en 2005 fue Broadcast Yourself ("Emite tú mismo" o "Emítete").

El precursor de esta nueva etnografía banal de Youtube ha sido el antropólogo Michael Wesch, que ha desarrollado un elaborado instrumental teórico y metodológico para explorar las posibilidades expresivas del audiovisual amateur. Wesch ha llevado a cabo investigaciones que tratan de construir crónicas cotidianas a través del registro de webcams, narrativas del día a día basadas en la autoexposición digital (Wesch, 2009). Tanto que, para el propio antropólogo norteamericano, los nuevos medios audiovisuales no solo introducen nuevas formas de expresarnos sino de autoconciencia (selfawareness) y reflexividad sobre quiénes somos y cómo nos relacionamos con el otro en un mundo global (Wesch, 2009: 19). Esta línea de investigación también ha explotado con eficacia fuentes audiovisuales relacionadas con el entretenimiento homecasting (por oposición al broadcasting, Van Dijk, 2007), los autoretratos visuales prosaicos y las memorias audiovisuales de la población internauta que participa en canales de maquillaje, cocina o bricolaje mediante cámaras fijas instaladas en el ordenador. En estos trabajos, lo que desde una perspectiva tradicional sería considerado como estética ramplona y trivial es reinterpretado como un dato natural, veraz y más cercano al quehacer del usuario que otro tipo de registros audiovisuales elaborados? ${ }^{9}$. Por eso,

8 Aparece dicho término en su tesis doctoral y en las entrevistas realizadas: http://henryjenkins. org/2007/10/vernacular_creativity_an_inter.html

9 En este sentido, resulta interesante esta entrevista con Godard de 2011 en torno a este

EMPIRIA. Revista de Metodología de Ciencias Sociales. N. . 35, septiembre - diciembre, 2016, pp. 105-124. ISSN: 1139-5737, DOI/ empiria.35.2016.17170 
para Wesch el análisis del self-recording (auto-grabado) con webcams es un elemento antropológico crucial que permite rescatar categorías relevantes de la identidad contemporánea, constituyendo una especie de registro en tiempo real de la actividad del sujeto libre en el capitalismo tardío ${ }^{10}$. De hecho, sería completamente equivocado pensar que la etnografía de Youtube y plataformas similares se reduce al estudio del audiovisual rústico, las caídas caseras y el humor con mascotas. La "observación flotante" (De Pedro y Rosauro, 2015) es una técnica fructífera de análisis de la cotidianeidad realmente existente que se ha empleado para explorar los contornos de lo público y lo privado (Lange, 2007), la autoexpresión de colectivos estigmatizados (Raun, 2016, por ejemplo, explora el uso de canales Youtube por la comunidad transexual) o de distintos movimientos sociales (McCosker, 2015).

De alguna manera, este nuevo documentalismo multimedia constituye una reelaboración novedosa y con indudables puntos de interés de concepciones socioantropológicas de lo cotidiano y lo ordinario que, en el fondo, son muy clásicas. Las etnografías virtuales de multitudes online autograbadas en sus quehaceres diarios permiten una especie de retorno reflexivo desde la postmodernidad a la vieja aspiración de la época heroica de la antropología de encontrar un objeto de investigación incontaminado que hablara espontáneamente de sí mismo. En este sentido, esta clase de planteamientos, se enfrenta a un típico problema de circularidad hermenéutica: hasta qué punto la naturalidad de los vídeos caseros de estas plataformas no es un producto profundamente elaborado y artificial de nuestra contemporaneidad postmoderna. Es habitual, por ejemplo, que en el contexto de las plataformas audiovisuales se desprecie y se denuncie los fakes pseudoamateurs, aquellos vídeos que se hacen pasar por caseros y espontáneos pero, en realidad, han sido preparados. Este desprecio culturalmente construido de la artificialidad da a entender que la naturalidad de los self-recordings de Youtube es una especie de espontaneidad de segundo grado, autoconsciente y profundamente mediada: un neopositivismo paradójico, por así decirlo.

\section{MEMÉTICA Y CULTURA EN LAS REDES}

Las manifestaciones culturales que tienen lugar en espacios como Youtube suelen estar moduladas por las condiciones de popularidad de los vídeos. Las barreras de acceso económicas y tecnológicas han sido sustituidas por enormes desigualdades en la difusión de unos contenidos frente a otros: hay un puñado de usuarios que sistemáticamente tienen millones de visitas y miles de comentarios

asunto (http://www.zeit.de/2011/41/Interview-Godard):

Die Zeit: Do you concern yourself with new media and technology?

Jean-Luc Godard: I try to keep up. But people make films on the Internet to show that they exist, not in order to look at things.

10 Al punto que las cámaras go-pro que pueden incorporarse de manera móvil reflejan un poco esta idea: http://www.eldiario.es/rastreador/hooligans-Rusia-GoPro-Eurocopa_6_526757338.html 
y una inmensa masa de productores anónimos cuyos vídeos, en cambio, pasan completamente desapercibidos. Estaríamos ante los típicos procesos de popularidad mediática y artística clásica, esta vez en espacios aparentemente abiertos y singulares: una especie de "efecto Mateo" digital. En ese sentido, otro importante ámbito de investigación en el ámbito audiovisual online ha sido las aplicaciones de la memética, es decir, el estudio de las unidades de difusión de la información (audiovisual en este caso) por los circuitos de Internet, analizando la composición de las comunidades de usuarios capaces de viralizar determinados contenidos (Shifman, 2012).

La memética es una teoría de la transmisión cultural desarrollada por Dawkins (2000) y Dennett (1995) que se inspira metafóricamente en la biología genética para estudiar cómo se comparte la información cultural por mecanismos de imitación, replicación y asimilación. El paralelismo entre la evolución genética y la reproducción cultural ha dado mucho juego y se han identificado replicadores culturales y mecanismos de difusión a partir de la idea de patrones culturales (o cuantos de información) que, a modo de paquetes, se propagan por las redes y son transmitidos socialmente. En esa línea, por ejemplo, Susan Blackmore desarrolló en La máquina de los memes (2000), el concepto de "teme" o "meme tecnológico", con el que pretendía dar soporte teórico a las manifestaciones culturales de las redes sociales. Se trata de un elenco teórico sugerente y muy útil para los estudios de viralización y que ha llevado a desarrollar metodologías específicas para el análisis de la difusión de documentos audiovisuales (Feroz-Khan y Vong, 2014). La viralidad, por tanto, se ha convertido en técnica de investigación propia que parece otorgar información suficiente sobre la entidad o situación del audiovisual online y que ha sido aplicada a numerosos ámbitos como, por ejemplo, la publicidad (Leonhardt, 2015).

Una de las estrategias más habituales dentro de esta tradición de análisis consiste en recuperar una crítica clásica a la comprensión del público como una masa indiferenciada -cada uno de cuyos miembros recibe personal pero homogéneamente el mensaje emitido- que, en cambio, trata de detectar la existencia de un grupo específico de personas "muy implicadas e interesadas por el tema, y dotadas de más conocimiento sobre el mismo" (Lazarsfeld, Berelson \& Gaudet, 1948:49). La noción de two-step flow of communication, importante en este contexto, alude precisamente a la idea de que la mayor parte de la gente forma sus ideas bajo la influencia de líderes de opinión muy concretos. Las redes sociales contemporáneas exacerban esta lógica que, en el ámbito digital, alcanza ritmos epidemiológicos. En el caso de Youtube y otras plataformas audiovisuales, hay personas que han obtenido una gran visibilidad y credibilidad en su entorno social digital -en especial cuando tienen un gran número de seguidores-y, así, cuentan con la capacidad de influir en las opiniones de buena parte del público (los denominados youtubers).

A pesar de que las asimetrías de influencia son un fenómeno determinante en la lógica de las redes audiovisuales, su análisis no deja de ser problemático. Es fácil sobredimensionar el peso y la coherencia de los influencers y, en cambio, 
infravalorar la complejidad e impredecibilidad de los procesos que se dan en los entornos digitales distribuidos. Como señalaba Duncan Watts: "En vez de pensar en las redes como entidades que evolucionan, los analistas de redes han tendido de hecho a tratarlas como una materialización congelada de esas fuerzas. Y en vez de entender las redes como meros conductos a través de los cuales la influencia se propaga según sus propias reglas, han tratado a las propias redes como una representación directa de la influencia" (2004: 52).

De hecho, algunos autores (Gómez, 2015) han alertado de que el concepto de medio viral se basa en dos ideas cuando menos cuestionables. En primer lugar, presupone una cierta pasividad del usuario, que es un simple portador de los videos "infectados" con independencia de sus características sociales (un sujeto inactivo que rebota y clickea). En segundo lugar, asume cierta "neutralidad" de los mensajes y los materiales fílmicos, como si fueran elementos puros que circulan por las redes volando de emisores a receptores sobre un contexto ausente. Lo cierto es que la circulación en las redes sociales no es un mero juego automático entre consumidores pasivos y superestructuras mediáticas, sino que existen usuarios segmentados según variables sociológicas relevantes con capacidades diferenciales para apropiarse, alterar, negociar o redifundir los contenidos en marcos históricos concretos. Por ello, algunos autores han propuesto la idea de "spreadable media" (Stein et al., 2015), intentando enfatizar la actividad de los consumidores multiplicadores del contenido multimedia. En ese sentido, más que constatar asépticamente la replicación de memes por razones topológicas y reticulares sería necesario explicar la difusión, el control y la distribución de los mensajes en función de factores sociológicos.

\section{LA AUDIENCIA COMO COMUNIDAD SOBERANA Y EMPODERADA}

Aunque, como hemos visto, la idea de que en plataformas audiovisuales como Youtube se forman "comunidades" de usuarios no es ni mucho menos evidente ni teóricamente neutra, es un presupuesto teórico que determina, casi siempre sin discusión, cuestiones metodológicas centrales, en particular aquellas relacionadas con la construcción de muestras (Light et al, 2012). Es decir, lo que la comunidad decide o elige, valora o ningunea, puntúa o ignora, se toma inmediatamente como material a analizar. Es lo que algunos autores han llamado un "automuestreo" que, de algún modo, reconoce la soberanía metodológica de la comunidad para seleccionar los vídeos a analizar. Muchas aproximaciones metodológicas al audiovisual digital han enfocado directamente sus estudios hacia el lugar donde las audiencias han señalado, como si su mero interés manifestado a través de likes, comentarios, favoritos y similares expresiones de adhesión fueran un criterio crucial para definir un objeto de estudio. De esta forma, una serie de métricas en general cuantitativas y altamente correlacionadas entre ellas que miden operativamente el comportamiento comunitario (viewcount, \#comments, \#ratings, \#favorites) se 
utilizan con frecuencia como muestreo directo.

Así, por ejemplo, Berrocal et al. (2012) analizan los vídeos políticos más populares (con más reproducciones). Williams et al. (2014), igualmente, aplicando diez términos de búsqueda sobre educación y salud seleccionaron los cien videos con mayor número de visionados para poder analizar el contenido. Finalmente, Tuells et al. (2015) en su estudio y registro sobre el virus del papiloma humano y su representación mediante videos de Youtube encontraron inicialmente 1080 que fueron recortando hasta llegar a los veinte más visitados. De esta forma, la popularidad, adhesión o la viralidad -expresadas mediante puntuaciones, rankings, medidas de aprobación y seguimiento, etc. - se convierten en un filtro crucial a la hora de seleccionar los datos y definir el objeto de estudio. Asimismo, la capacidad de propagación entre un público invisible conectado globalmente adquiere una gran preponderancia selectiva en detrimento del contenido de los audiovisuales.

Esta estrategia no es en sí misma negativa, siempre que se tenga presente que depende de algunos presupuestos metodológicos importantes que seguramente serían cuestionados en casi cualquier otro área de la investigación social. En particular, implica una confianza un tanto peculiar en la dimensión agregativa y demoscópica de las audiencias que necesariamente deja de lado o al menos minimiza la influencia de modas, tendencias, sesgos, estadísticas infladas y otros fenómenos. Al fin y al cabo, los instrumentos a través de los que las audiencias expresan su aprobación o su disgusto no son formas espontáneas de autoexpresión sino dispositivos tecnológicos minuciosamente creados por empresas para potenciar ciertos resultados y que, como mínimo, pueden producir sesgos significativos. En última instancia, esta aceptación de Youtube como un terreno, por así decirlo, preoperacionalizado es un subproducto de la conceptualización de los públicos online como multitudes inteligentes y, en términos de Jenkins, "empoderadas" (o "comunidades de conocimiento", 2006: 243), cuyas apropiaciones son el resultado de la inteligencia colectiva ${ }^{11}$. De hecho, Santos et al. (2007) han realizado un análisis de redes profundo de comunidades de Youtube llegando a la conclusión de que los factores sociales son mucho más relevantes que los meramente tecnológicos como elemento agregador o cemento constitutivo. Es decir, la adhesión y el gusto no son visionados libres de usuarios independientes sino que muchas veces están condicionados por sociabilidades previas (offline) mientras que, por otra parte, las comunidades audiovisuales online no interaccionan con facilitad entre ellas.

11 No obstante, este autor hace una distinción crucial entre interacción o interactividad y participación, dos términos que se utilizan sin apenas matices de forma indistinta. Jenkins considera que el primero se refiere a modos de comportamiento dependientes del diseño tecnológico mientras el segundo vendría condicionado por reglas y normas socioculturales (Jenkins, 2006: 138-139). 


\section{LOS NUEVOS GÉNEROS DEL AUDIOVISUAL ONLINE}

Existe una importante familia de estudios audiovisuales que van más allá del análisis de contenido de los vídeos e investigan en qué medida las plataformas digitales audiovisuales determinan condiciones narrativas peculiares que afectan a la naturaleza de los contenidos compartidos. Desde esta perspectiva, se aborda el audiovisual como máxima expresión de una nueva cultura mediática que hay que desentrañar a través de estrategias deconstructivas dirigidas al cartografiado de sus "géneros" de narración audiovisual. Estas investigaciones analizan "la forma Youtube" (y sus derivados), escudriñando la especificidad discursiva y compositiva de los vídeos que genera. La idea es que, parafraseando a McLuhan, la plataforma es el mensaje, de modo que los vídeos adaptan sus formatos a las condiciones del medio electrónico.

En este contexto, Burgess ha planteado la existencia de dos géneros predominantes o formas estéticas hegemónicas en Youtube, que denominó "géneros-Youtube" (2011: 5) y que son relevantes en términos de investigación social. En primer lugar, estaría el "live performance": la grabación de usuarios en actitudes cotidianas o informales ante una cámara, especialmente en espacios domésticos (este sería, como hemos visto, el objeto privilegiado de las etnografías digitales). A este primer género pertenecen los vídeos amateurs que aspiran a auto-representarse en lo cotidiano, empoderándose como autores capaces de autofilmarse, de narrar en primera persona su "estar en el mundo". El segundo género es del de los "vídeos virales" -en especial las parodias, mezclas o grabaciones impactantes- cuyas características narrativas están asociadas a su potencia memética en términos de visibilidad, popularidad y la reproductibilidad reticular (que también hemos mencionado en epígrafes anteriores). Este segundo género guardaría relación, a su vez, con el empoderamiento de las audiencias y su capacidad para optar por determinadas manifestaciones audiovisuales, evidenciando sus preferencias y decisiones por encima de una parrilla impuesta o una programación ya decidida. Ambos serían nuevos modos de participación e interacción peculiares de estas plataformas, unas basadas en la cámara en vivo (usuarios) y otras en la demoscopia online (comunidades).

Así, por ejemplo, Pérez Rubí et al. (2014) identifican en Youtube una narrativa del videoclip musical diferente y novedosa a partir de una muestra de cincuenta vídeos. También se han estudiado abundantemente los denominados VBlogs (videoblogs), galerías de vídeos ordenados cronológicamente, donde un autor/creador expone sus ideas sobre algún tema (arte medieval, bricolaje casero, gastronomía hindú, sexo tántrico, etc.) y permite la interactividad con otros usuarios por medio de los comentarios y las respuestas en vídeo. Este tipo de narración visual a base de sucesiones encadenadas de vídeos temporales constituye un género particular inexistente hace unos años. Por supuesto, se han extendido hacia géneros hermanos como la memoria histórica (Smit et al., 2015), el videoactivismo (Askanius, 2012), los problemas socioeconómicos (Triliva et al., 2015), educativos (Antonio y Tuffley, 2015), etc. Otro ejemplo paradigmático son los VideoBlogs de colectividades como los pacientes que

EMPIRIA. Revista de Metodología de Ciencias Sociales. N. . 35, septiembre - diciembre, 2016, pp. 105-124. ISSN: 1139-5737, DOI/ empiria.35.2016.17170 
han sobrevivido a un cáncer (Chou et al., 2011) que usan Youtube y otras plataformas para realizar catarsis audiovisuales o confesiones narrativas en primera persona.

Sin embargo, este modo de catalogar la vasta cantidad de registros videodigitales corre el riesgo de naturalizar una taxonomía absolutamente cultural y situada. Asumiendo como dados y cerrados estos géneros pareciera que son un mero reflejo del medio/estructura o de un diseño tecnológico neutro. Quizás, la existencia de los géneros no debería ser un a priori de la investigación sino un instrumento de aproximación cautelosa y abierta a modos culturales que se nutren tanto de lo online como de lo offline.

\section{EL MAL DE ARCHIVO}

El papel que cumplen las plataformas online no tanto ya como ágora participativa o plaza para la interacción sino como archivo público también resulta crucial para la investigación social. La mayoría de medios analógicos no disponen de la posibilidad de búsqueda y filtrado gratuito y recuperación de los materiales audiovisuales: obtener y utilizar un vídeo antiguo de una televisión convencional, por ejemplo, es un proceso largo, costoso y legalmente complicado. En cambio, en los repositorios digitales rebuscar en una acumulación masiva de materiales resulta sencillo, rápido y barato. Por eso muy pronto los investigadores comenzaron a animar a beneficiarse de esta gigantesca biblioteca de puertas abiertas (Snickars y Vonderau, 2009: 14).

En general, la dimensión acumulativa y libre de los medios online se tiende a considerar un valor netamente positivo para la investigación. La filosofía del Big Data ha tenido un gran impacto en este terreno y existe una clara propensión a mirar con buenos ojos cualquier reunión colosal de bytes, como si el mero sumatorio de materiales fuera en sí mismo valioso y mucho más relevante que la calidad de los datos. Los propios medios digitales alimentan esta dinámica de datificación con sus interfaces de archivo que facilitan la gestión de búsquedas, el acceso rápido y la organización autónoma de los registros por parte de cada usuario. La Biblioteca del Congreso de EEUU, por ejemplo, posee su propio canal de Youtube con más de 15 millones de ítems digitalizados (vídeos y audios). Estas iniciativas de "comunes digitales" parecen el sueño dorado del investigador social, cuyo reverso negativo es una especie de síndrome de Diógenes metodológico.

Es indudable que la minería de datos se ha convertido en un recurso de investigación fundamental en el capitalismo global informatizado, en el que las bases de datos gigantescas son una realidad material esencial. No obstante, también es cierto que al menos parte de los supuestos yacimientos de datos se parecen más a vertederos con escaso valor sociológico. Los repositorios digitales no siempre son bibliotecas de Alejandría sino que recuerdan a una especie de zapping entre canales televisivos de serie $\mathrm{B}$, en el que la acumulación de clips y grabaciones se convierte en ruido que dificulta las búsquedas. El catálogo de 
Youtube no es una versión digital de un pase de acceso ilimitado a los archivos de una televisión o de una filmoteca tradicional sino algo substancialmente distinto que se enfrenta a su propio conjunto de limitaciones. En ese aspecto inciden precisamente algunas críticas penetrantes que se han planteado a la calidad organizativa o a las estrategias de preservación de la información. Boyd y Crawford (2012) han realizado una acertada crítica de la ideología del Big Data no solo quejándose de la ecuación que iguala muchos datos a buenos datos sino reivindicando que en ocasiones pocos datos (muy relevantes) son la vía idónea para una buena práctica investigadora:

Finalmente, en este giro computacional, resulta cada vez. más importante reconocer el valor del "small data". Las ideas de investigación más iluminadoras pueden surgir en cualquier nivel, incluso en escalas muy modestas. En algunos casos, puede ser extraordinariamente valioso centrarse en un único individuo. Basta recordar, por ejemplo, el trabajo de Veinot (2007), que siguió a un empleado de una compañía hidroélectrica para entender las prácticas de información de un trabajador de cuello azul. Con este estudio inusual, Veinot redefinió la noción de "prácticas de información”, desplazando el foco de interés habitual -los trabajadores de cuello blanco que suelen ser usuarios pioneros- más allá del contexto urbano y las oficinas. Su trabajo cuenta una historia que no se podría haber descubierto cribando millones de cuentas de Facebook o Twitter, y contribuye a la investigación de un modo relevante, a pesar de que se basaba en un número de participantes extremadamente reducido. La magnitud de los datos debería adaptarse a la pregunta de investigación planteada; en algunos casos, lo pequeño es mejor (boyd y Crawford, 2012: 670).

\section{CONCLUSIÓN: LAS METÁFORAS DE YOUTUBE}

La profusión de discursos públicos promisorios en torno a las tecnologías de la comunicación hace que, inevitablemente, Youtube tienda a presentarse ante los ojos del investigador social en los entornos digitales como un santo grial instrumental que augura toda clase de avances y facilidades metodológicas (Konjin et al., 2013). La idea de una plataforma virtual donde los usuarios acceden y construyen colaborativamente una videoteca libre y abierta, una especie de cine público de proporciones colosales, resulta muy tentadora. Como ocurre en casi todos los ámbitos tecnológicos, el uso de metáforas facilita el acercamiento a las innovaciones pero también distorsiona la comprensión real de su sentido práctico. Las comparaciones de Youtube con la televisión, la industria fílmica, los medios analógicos o las instituciones culturales deben ser tomadas con precaución. Y lo mismo ocurre con las analogías con los archivos, las bibliotecas, las librerías y los registros: hay que sopesarlas cuidadosamente. Incluso cuando se define Youtube como un laboratorio de experimentación se 
corre el riesgo de acabar confundiendo deseo y realidad. La mayoría de estas plataformas no dejan de ser bases de datos enormes creadas en un contexto cultural determinado (en este caso el Big Data). Geert Lovink afirmó en cierta ocasión que vivimos en la era del "visionado de bases de datos" (we watch databases, Lovink, 2012: 9-10), en referencia a un nuevo modo de existencia del audiovisual en la era Internet que se caracteriza por el giro archivístico (database turn), la "buscabilidad" (searchability), la cultura fan, la cultura del video-clip (reducción temporal de la duración de los vídeos), etc.

En nuestro caso, en cambio, hemos identificado tres características fundamentales (acceso público, gran volumen y carácter amateur) que fijan las posibilidades de estas bases de datos audiovisuales para la investigación social. A partir de ellas, hemos descrito al menos cinco modelos metodológicos innovadores encarnados en diferentes estudios e investigaciones académicas y públicas: i) la visibilidad de la audiencia (estudios de recepción y comentarios), ii) las etnografías de la banalidad digital, iii) la memética y viralidad de videos en las redes, iv) los nuevos géneros audiovisuales y v) la audiencia como comunidad soberana (o generadora de las muestras). Para cada uno de estos modos de investigar hemos tratado de sacar a la luz supuestos subyacentes y asunciones teóricas tácitas que puede ser cuestionados y debatidos. En general, sólo mediante una crítica profunda de estas presuposiciones podremos avanzar en la práctica sociológica audiovisual.

Sin embargo, nos gustaría remarcar que no solo merece la pena visibilizar los problemas asociados a las metodologías de estudio del audiovisual online (Youtube, principalmente). También habría que recoger, a partir de lo anterior, el tipo de preguntas que este objeto de investigación proyecta sobre los propios métodos y técnicas de investigación aplicados en ciencias sociales; es decir, de qué manera un espacio social complejo y novedoso obliga a reconfigurar la práctica metodológica. Lo digital puede llegar a hacernos repensar qué es un método, cómo se aplican y circulan las metodologías en ciencias sociales, bajo qué supuestos las hacemos funcionar y cómo se legitiman y valoran (dónde y cómo se producen). El análisis de plataformas como Youtube o de las tecnologías en red para compartir materiales visuales saca a la luz conflictos y limitaciones generales de los estándares investigadores clásicos y de la metodología protocolizada de manual. Todo ello nos conduce a examinar los principios epistemológicos y metodológicos fundamentales de las ciencias sociales que, en muchos casos, son alterados desde espacios no académicos. Es lo que Marres denomina la "redistribución de los métodos" (Marres, 2012). De alguna manera, este trayecto parte de cómo las diversas investigaciones de lo audiovisual en Internet nos permiten problematizar qué es "lo audiovisual" para acabar problematizando "qué es investigar".

Como conclusión final, en función de la conceptualización que hagamos de este tipo de espacios de interacción online podremos comprender su uso y aproximación metodológica más pertinente. Sin embargo, en todo momento hay que estar alerta para no resbalar por una metáfora inadecuada cuyas consecuencias no dejan de ser promesas y expectativas dudosas. La 
metaforización del universo digital siempre abre horizontes de actuación preñados de esperanza. Pero, igualmente, puede generar investigación social sobre una base endeble. Una metodología que haga un uso coherente del audiovisual online y sus repositorios debería ser consciente tanto de sus posibilidades como de sus limitaciones.

\section{BIBLIOGRAFÍA}

ADAMI, E. (2010): "Contemporary Patterns of Communication: The case of vídeointeraction on YouTube". Saarbrucken: Lambert Academic Publisher.

ADAMI, E. (2012) "Affordances and Practices: the case of Youtube vídeo responses" en Web genres and Web tools, Ibis, Pavia, pp. 235-256.

ANDROUTSOPOULOS, J. (2011): "From variation to heteroglossia in the study of computer-mediated discourse" en Digital discourse: Language in the new media, pp. 277-298.

ANTONIO, A., \& TUFFLEY, D. (2015): "YouTube a valuable educational tool, not just cat videos", The Conversation, 16.

ARROYO, I. M BAÑOS, C VAN-WYCK (2013): “Análisis de los mensajes audiovisuales del Tercer Sector en YouTube", en Revista Latina de Comunicación Social, 68.

BEDDOWS, E. (2008): "The Methodological Issues Associated With Internet-Based Research", International Journal of Emerging Technologies and Society, Vol. 6, No. 2, 2008, pp: $124-139$.

BERGER, J. (2008): Ways of seeing, Penguin UK.

BERROCAL，S., DOMÍNGUEZ, E. C., \& GARCÍA，M. R. (2012): “El «infoentretenimiento» en Internet. Un análisis del tratamiento político de José Luis Rodríguez Zapatero, Mariano Rajoy, Gaspar Llamazares y Rosa Díez en YouTube”, Doxa Comunicación: revista interdisciplinar de estudios de comunicación y ciencias sociales, (15), 13-34.

BLOOM, K., \& JOHNSTON, K. M. (2013): "Digging into YouTube videos: Using media literacy and participatory culture to promote cross-cultural understanding", Journal of Media Literacy Education, 2(2), 3.

BOYD, D. \& CRAWFORD, K. (2012): Critical Questiones for Big Data. Information, Communication \& Society, 15:5, 662-679.

BOYD, D. M., \& ELLISON, N. B. (2012): Social network sites. Online Communication and Collaboration: A Reader. En Dutton, W. H. (Ed.), The Oxford Handbook of Internet Studies. Oxford: Oxford University Press, pp. 151172.

BURGESS, J. Y GREEN, J. (2009): YouTube: Online Vídeo and Participatory Culture. Politiy Press.

CALLEJO, J. (2001): Investigar las audiencias: un análisis cualitativo. Madrid: Paidós.

CASTELLS, M. (1999): La sociedad red. La era de la información: economía, sociedad y cultural. Alianza Editorial, Madrid.

- (2009): Comunicación y Poder. Madrid: Alianza Editorial.

- (2012): Redes de indignación y esperanza: los movimientos sociales en la era de Internet. Alianza Editorial. 
CUKIER, K. Y MAYER-SCHÖNBERGER, V. (2013): Big data. La revolución de los datos masivos. Turner Noema. Barcelona.

CHAU, C. (2010): "YouTube as a participatory culture", New Directions for Youth Development: $65-74$.

CHOU, W. Y. S., HUNT, Y., FOLKERS, A., \& AUGUSTSON, E. (2011): "Cancer survivorship in the age of YouTube and social media: a narrative analysis", Journal of medical Internet research, 13(1), e7.

DE PEDRO, A. y ROSAURO, E. (Coord.) (2015): Cómo ver cómo. Textos sobre cultura visual latinoamericana, Editorial Foc S.L.,

ESTALELLA, A., \& ARDÉVOL, E. (2011): “e-Research’: desafíos y oportunidades para las ciencias sociales", Convergencia, 18(55), pp. 87-111.

EYNON, R., SCHROEDER, R., \& FRY, J. (2009): New techniques in online research: Challenges for research ethics. Twenty-First Century Society, 4(2), 187-199.

FIELDING, N., LEE, R. Y BLANK, G. (Eds.) (2008): The Handbook of Online Research Methods, Sage, Londres.

FEROZ KHAN, G., \& VONG, S. (2014): "Virality over YouTube: an empirical analysis", Internet Research, 24(5), 629-647.

GAUDENZI, S. (2014): "Strategies of participation: the who, what and when of collaborative documentaries" en New Documentary Ecologies (pp. 129-148). Palgrave Macmillan UK.

GEISLER, G., \& BURNS, S. (2007): "Tagging video: conventions and strategies of the YouTube community", en Proceedings of the 7th ACM/IEEE-CS joint conference on Digital libraries (pp. 480-480). ACM.

GÓMEZ, A. D. (2015): “Aproximación téorica al concepto de viralidad desde el punto de vista de comunicación: aplicación y repercusiones en los contenidos publicitarios audiovisuales" en El nuevo diálogo social: organizaciones, públicos y ciudadanos (pp. 601-612). Valencia, Campgrafic.

HINE, C. (2004): Etnografía Virtual. UOC, Barcelona.

- (2005): Virtual Methods: Issues in Social Research on the Internet, Berg Publishers, Oxford.

- (2015): Ethnography for the Internet. Embedded, embodied and everyday. Bloomsbury Publishing. Oxford.

JAMES, N., \& BUSHER, H. (2013): "Credibility, Authenticity and Voice: Dilemmas in Online Interviewing", Qualitative Research 3, 403-420.

JENKINS, H. (2006): Convergence Culture: Where old and new media collide. New York: New York University Press.

KAVADA, A. (2012): "Engagement, bonding, and identity across multiple platforms: Avaaz on Facebook, YouTube, and MySpace", MedieKultur: Journal of media and communication research, 28(52), 21.

KEEN, A. (2011): The Cult of the Amateur: How Blogs, MySpace, YouTube and the Rest of Today's User Generated Media are Killing Our Culture, Nicholas Brealey Publishing.

KONIJN, E. A., VELDHUIS, J., \& PLAISIER, X. S. (2013): "YouTube as a research tool: Three approaches", Cyberpsychology, Behavior, and Social Networking, 16(9), 695-701.

KOZINETS, R. V. (2015): Netnography, Londres, John Wiley \& Sons, Inc..

LANGE, P. G. (2007): "Publicly private and privately public: Social networking on YouTube", Journal of Computer-Mediated Communication, 13(1), 361-380. 
LAZARSEFELD, P. F., BERELSON, B., Y HAZEL, G. (1944): The People's Choice: How the Voter Makes Up His Mind in a Presidential Campaign. (Second edition.). New York: Columbia University Press.

LEONHARDT, J. (2015): "Going viral on YouTube", Journal of Digital \& Social Media Marketing, 3(1), 21-30.

LIGHT, B., GRIFFITHS, M., \& LINCOLN, S. (2012): “Connect and create’: Young people, YouTube and Graffiti communities”, Continuum, 26(3), 343-355.

LOVINK, G. (2012) "The Art of Wat ching Databases. Introduction to the Video Vortex Reader", en Lovink, G. y Niederer, S. The Vortex Reader: Responses to Youtube. Institute of Network Cultures. Amsterdam.

MARKHAN, A. Y BAYM, N. (2008): Internet Inquiry: Conversations About Method, Sage, Londres.

MARRES, N. (2012): "The redistribution of methods: on intervention in digital social research, broadly conceived", The Sociological Review 60:139-165.

MCCOSKER, A. (2015): "Social Media Activism at the Margins: Managing Visibility, Voice and Vitality Affects", Social Media \& Society, 1(2).

MORENO, A. M. (2014): “Banalidades virales? Algunas consideraciones acerca de "vídeos divertidos" en Youtube", Comunic@Red vol 1. Nº1.

OKSANEN, A., GARCIA, D., SIROLA, A., NÄSI, M., KAAKINEN, M., KEIPI, T., \& RÄSÄNEN, P. (2015): "Pro-anorexia and anti-pro-anorexia videos on YouTube: Sentiment analysis of user responses", Journal of medical Internet research, 17(11).

PAEK, H. J., KIM, K., \& HOVE, T. (2010): “Content analysis of antismoking videos on YouTube: message sensation value, message appeals, and their relationships with viewer responses", Health Education Research, 25(6), 1085-1099.

PÉREZ RUFÍ, J. P., GÓMEZ PÉREZ, F. J. \& NAVARRETE CARDERO, J. L. (2014): "El videoclip narrativo en los tiempos de YouTube". Sphera Publica, 2, (14), 36---30

POYNTER, R. (2010): The Handbook of online and social media research, Wiley, Sussex.

PURCELL, K. (2010): “The state of online video". Pew Research. Descargado de: http:// www.pewInternet.org/Reports/2010/State-of-Online-Video.aspx

RAUN, T. (2016): Out Online: Trans Self-Representation and Community Building on YouTube, Routledge, Londres.

ROSE, G. (2016): Visual methodologies: An introduction to researching with visual materials, Londres, Sage.

SANTOS, R. L., ROCHA, B. P., REZENDE, C. G., \& LOUREIRO, A. A. (2007): Characterizing the YouTube video-sharing community. Federal University of Minas Gerais (UFMG), Belo Horizonte, Brazil, Tech. Rep.

SHIFMAN, L. (2012): “An anatomy of a YouTube meme”, New media \& society, 14(2), 187-203.

SMIT, R., HEINRICH, A., AND BROERSMA, M. (2015): "Witnessing in the new memory ecology: Memory construction of the Syrian conflict on YouTube", New Media \& Society, 1-16.

SNICKARS, P. Y VONDERAU, P. (2009): The Youtube Reader. National Library of Sweden, Estocolmo.

STEIN, L., JENKINS, H., FORD, S., GREEN, J., BOOTH, P., BUSSE, K., \& ROSS, S. (2014): "Spreadable media: Creating value and meaning in a networked culture", Cinema Journal, 53(3), 152-177. 
TUELLS, J., MARTÍNEZ-MARTÍNEZ, P. J., DURO-TORRIJOS, J. L., CABALLERO, P., FRAGA-FREIJEIRO, P., \& NAVARRO-LÓPEZ, V. (2015): "Características de los vídeos en español publicados en Youtube sobre la vacuna contra el virus del papiloma humano", Revista Española de Salud Pública, 89(1), 107-115.

RHEINGOLD, H. (2004): Multitudes inteligentes, Barcelona, Gedisa.

THELWALL, M., SUD, P. AND VIS, F. (2012): "Commenting on YouTube videos: From guatemalan rock to El Big Bang”, J. Am. Soc. Inf. Sci., 63: 616-629. doi: 10.1002/asi.21679

THURLOW, C., \& MROCZEK, K. (2011): Digital discourse: Language in the new media, Oxford University Press on Demand.

TRILIVA, S., VARVANTAKIS, C., \& DAFERMOS, M. (2015): "YouTube, young people, and the socioeconomic crises in Greece", Information, Communication \& Society, 18(4), 407-423.

YANG, K. H. (2013): "A reflection on a participatory video project: Possibilities and challenges for promoting participatory cultures among adult learners", The Urban Review, 45(5), 671-683.

VAN DIJK, J. (2007): Television 2.0: YouTube and the emergence of homecasting. Creativity, Ownership and Collaboration in the Digital Age, Cambridge, Massachusetts Institute of Technology, 27-29.

WATTS, D. (2004): Six degrees: the new science of networks. Random House.

WESCH, M. (2009): "YouTube and You: Experiences of Self-awareness in the Context Collapse of the Recording Webcam", Explorations in Media Ecology, 8(2), 19-34.

WHITEMAN, N. (2012): "Undoing Ethics" en Undoing Ethics (pp. 135-149). Springer US.

WILLIAMS, D., SULLIVAN, S. J., SCHNEIDERS, A. G., AHMED, O. H., LEE, H., BALASUNDARAM, A. P., \& MCCRORY, P. R. (2014): "Big hits on the small screen: an evaluation of concussion-related videos on YouTube". British journal of sports medicine, 48(2), 107-111. 